\title{
Stage IVA Pharyngeal Cancer
}

National Cancer Institute

\section{Source}

National Cancer Institute. Stage IVA Pharyngeal Cancer. NCI Thesaurus. Code C6000.

Stage IVA carcinoma of the pharynx according to the American Joint Committee on

Cancer, 6th, 7th, and 8th editions. 